\title{
Porencephaly diagnosed by isotope cisternography
}

\author{
D. FRONT, J. W. F. BEKS, AND L. PENNING ${ }^{1}$ \\ From the Departments of Neuroradiology and Neurosurgery, University Hospital, Groningen, \\ The Netherlands
}

SUMMARY The diagnosis of porencephaly by isotope cisternography is described. In the three cases presented, porencephaly was associated with non-resorptive hydrocephalus. The communicating hydrocephalus caused the isotope to enter the ventricular system and visualize the cyst, and the diagnosis of both disorders was established by RIHSA cisternography. The method is simple and non-traumatic and provides information about abnormalities which air may fail to demonstrate.

Isotope cisternography has proved to be very useful in the diagnosis of disturbances of flow and absorption of cerebrospinal fluid (CSF) and their resultant hydrocephalus (Di Chiro, Reames, and Matthews, 1964; Bannister, Gliford, and Kocen, 1967; James, DeLand, Hodges, and Wagner, 1970; Front, 1971), and in the recognition of CSF rhinorrhoea (Di Chiro and Grove, 1966; Di Chiro, Ommaya, Ashburn, and Briner, 1968; Front and Penning, 1971).

In addition, we have found this investigation to be very valuable in the diagnosis of local abnormalities of the CSF spaces. In this paper three cases will be described in which porencephaly was diagnosed by isotope cisternography.

\section{METHOD}

Radioiodinated human serum albumin (RIHSA) is used. Routinely $100 \mu \mathrm{Ci}$ are injected into the lumbar theca. Freshly prepared RIHSA of high specific activity $(1 \mathrm{mg}$ albumin/100 $\mu \mathrm{Ci})$ is used. The thyroid gland is blocked by three drops of Lugol's solution daily for nine days, starting one day before the investigation. Each study is performed with both a scintillation gamma camera (Pho Gamma III Nuclear Chicago) and a rectilinear scanner (Pho dot, Nuclear Chicago). There are several reasons for this. A preliminary study with the gamma camera gives a quick general orientation and suggests whether it is necessary to use views and positions besides the routine anterior and lateral ones. The rectilinear scanner gives somewhat better resolution in the

1 Reprint requests: Professor Dr. L. Penning, University Hospital, Department of Neuroradiology, Groningen. The Netherlands. plane of the collimator than does the gamma camera. Every patient is studied at four, 24, and 48 hours after injection.

\section{CASE 1}

A 39 year old man suffered a head injury in a road accident. Bleeding was noticed from his nose and mouth but no abnormality was found on neurological examination. Plain radiographs of the skull showed fractures of the nasal, right maxillary, and zygomatic bones. Some days later his conscious level decreased, and he was found to have bitemporal hemianopsia and a dilated right pupil. There was some leakage of clear fluid from his nose. A right carotid angiogram was performed and this showed that both anterior cerebral arteries were pushed upwards, especially anteriorly, suggesting a space occupying lesion below them. Operation for correction of rhinorrhoea and exploration of the chiasmatic region showed a blood clot which was compressing the chiasm. The immediate post-operative course was uneventful, but his vision deteriorated and he showed signs of mental impairment. RIHSA cisternography was performed (Fig. 1). The four hour scintigrams showed filling of the ventricles in continuity with a large abnormal accumulation of radioactivity in the right frontal region. At the 24 hour examination no radioactivity was found over the brain convexities. At $\mathbf{4 8}$ hours the radioactivity in the ventricles was indistinct, but the abnormal frontal radioactivity was very marked. The results were thought to indicate a large right anterior porencephalic cyst, connected with the right lateral ventricle. The fact that no radioactivity was found over the brain convexities and that the ventricles were filled with the radiopharmaceutical indicated the 


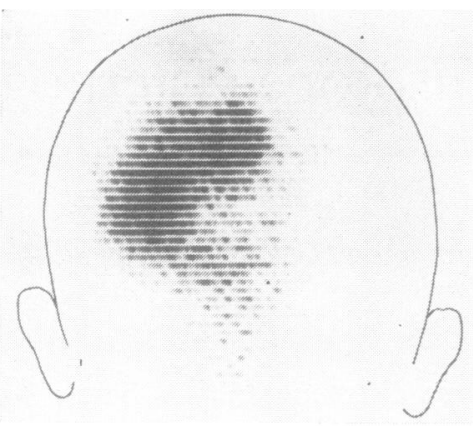

(a)

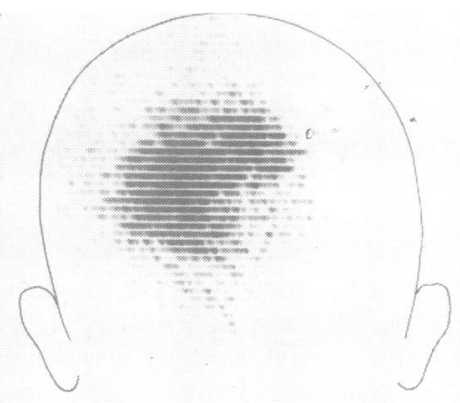

(c)

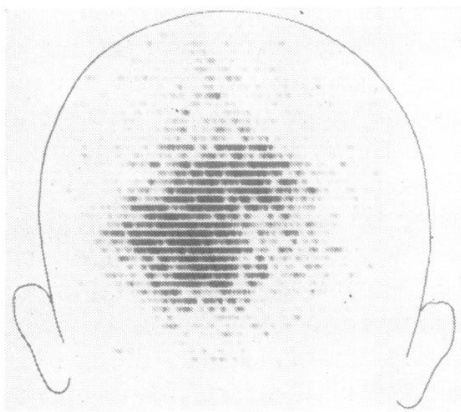

(e)

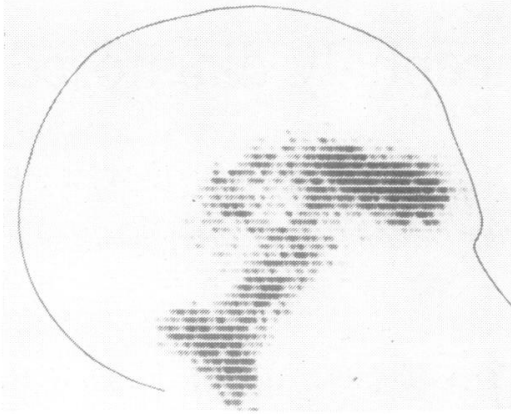

(b)

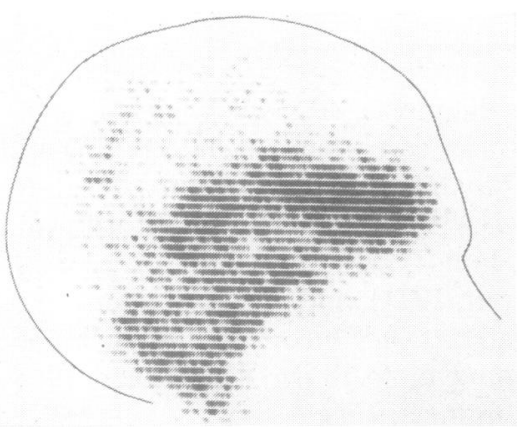

(d)

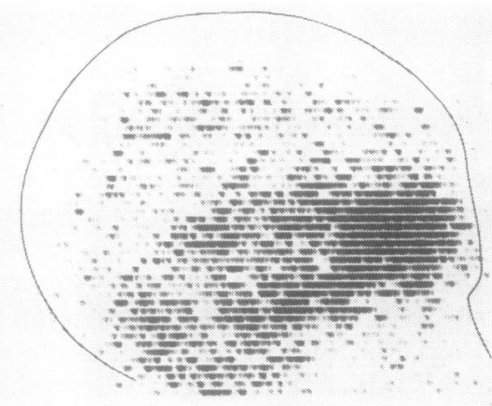

(f)

FIG. 1 RIHSA cisternography. Case 1. Porencephalic cyst and hydrocephalus. (a) Anterior and (b) lateral views at four hours. The radiopharmaceutical fills the cisterna magna, basal cisterns and mildly enlarged ventricles, and a large anterior cyst to the right of the midline. This cyst is in continuity with the anterior horn of $\frac{\circ}{\square}$ the right ventricle. (c) Anterior and (d) lateral views at 24 hours. Hardly any radioactivity is recorded over the $\frac{D}{2}$ brain convexities. The ventricles and the cyst are filled with the radiopharmaceutical. (e) Anterior and (f) lateral views at 48 hours. Most of the radioactivity is seen in the cyst and part of it in the ventricles. Little radioactivity $\tilde{N}$ is recorded over the brain convexities. 


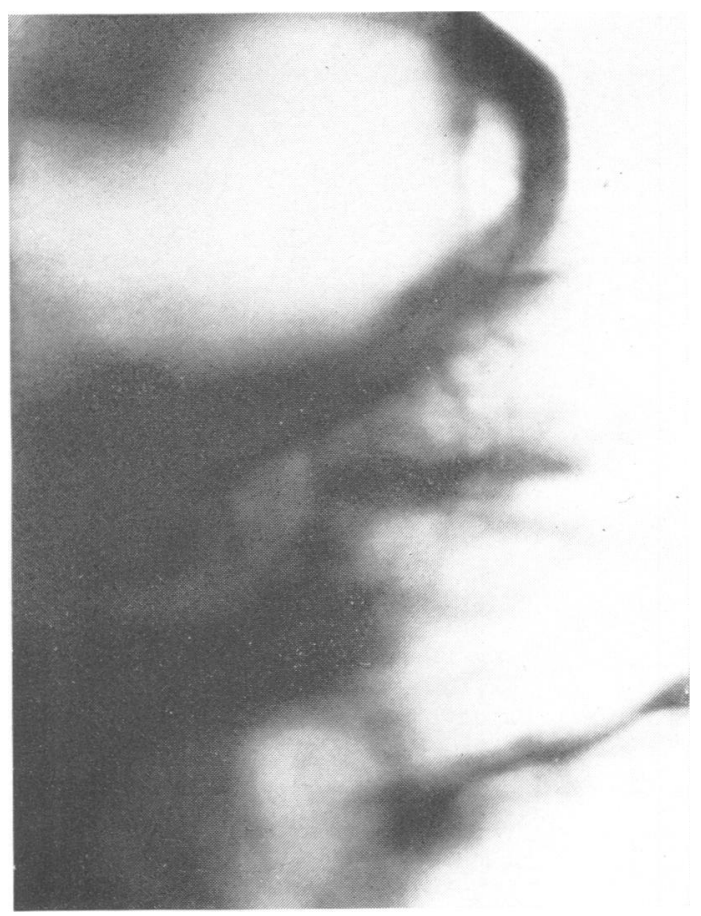

FIG. 2. Pneumoencephalography. Case 1. Porencephalic cyst and hydrocephalus. Lateral tomograms demonstrating the frontal cyst in continuity with an enlarged right ventricle.

presence of communicating non-resorptive hydrocephalus. Pneumoencephalography (Fig. 2) revealed a large anterior cyst communicating with the anterior horn of the right lateral ventricle, and dilated ventricles, thus confirming the findings of RIHSA cisternography.

At operation the cerebral cortex in the basal region of the right frontal lobe was very thin. It enclosed a brain cyst communicating with the anterior horn of the ventricle. The cyst was opened and communication was established between the right ventricle and the subarachnoid space. In view of the hydrocephalus a ventriculoatrial shunt was installed.

After operation his general condition and especially his mental state improved rapidly and markedly.

\section{CASE 2}

A 41 year old man was admitted because of recurrent attacks of pneumococcal meningitis probably related to rhinorrhoea. Nine years previously he had been admitted to another hospital because of a discharge of CSF from the nose. Radiographs of the skull had shown erosion of the sella and digitate impressions of the vault, obviously due to increased intracranial pressure. Tomograms had revealed a defect in the lamina cribrosa on the left side. During his stay in hospital he had developed pneumococcal meningitis which had responded to antibiotics. At operation several defects in the floor of the anterior fossa had been plugged with muscle and covered with fascia.

RIHSA cisternography (Fig. 3) during the present admission demonstrated filling of enlarged lateral ventricles, which persisted until 72 hours. No radioactivity was seen over the convexities. A large accumulation of abnormal activity was shown in the frontobasal region of the brain, continuous with the left lateral ventricle and overlying the anterior part of the roof of the nose. The results were interpreted as being due to a large anterior porencephalic cyst communicating with the anterior horn of the left lateral ventricle. The filling of the ventricles and the lack of radioactivity over the convexities indicated the presence of non-resorptive communicating hydrocephalus.

Pneumoencephalography (Fig. 4) demonstrated enlarged ventricles communicating with a porencephalic cyst of the left frontal lobe.

Operation revealed many defects in the floor of the left anterior fossa which were covered. The porencephalic cyst was opened so that it communicated with the subarachnoid space. The post-operative course was uneventful and slow recovery followed.

\section{CASE 3}

A 57 year old man suffered a head injury in a road accident. He was comatose, and was bleeding from the nose, ears, and mouth. A right oculomotor paresis was noticed. Plain radiographs of the skull showed fractures of the floor of the anterior fossa and right orbit. The patient slowly regained consciousness but remained very disoriented and confused. He complained of severe headaches, and his gait was markedly abnormal. An electroencephalograph (EEG) showed a right frontotemporal disturbance, and a brain scan showed an abnormal area of uptake in the right frontotemporal region. A right carotid angiogram did not demonstrate any space occupying lesion, but the thalamostriate vein was markedly displaced laterally, suggesting hydrocephalus. Pneumoencephalography confirmed the presence of hydrocephalus but did not show any other abnormality. RIHSA cisternography (Fig. 5) was undertaken: at four hours it showed filling of markedly enlarged ventricles, and at 24 hours a large abnormal accumulation of radioactivity was seen lateral to the right 


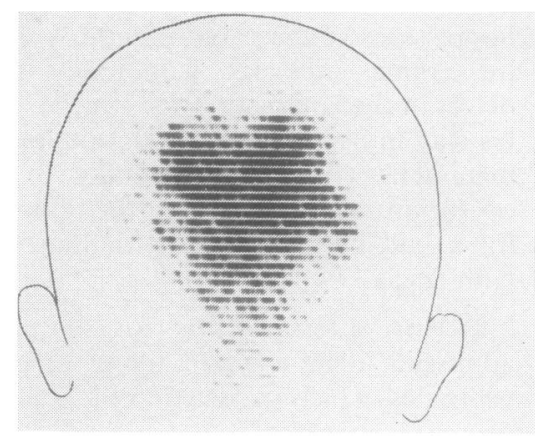

(a)

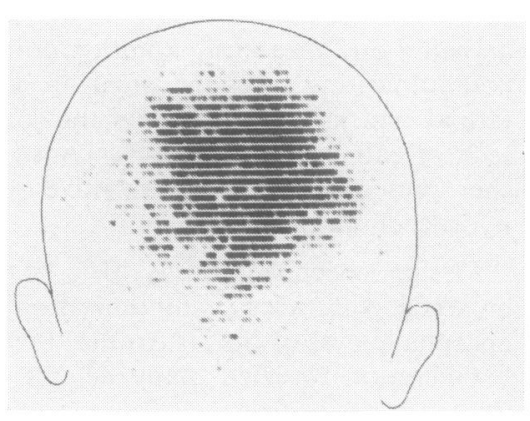

(c)

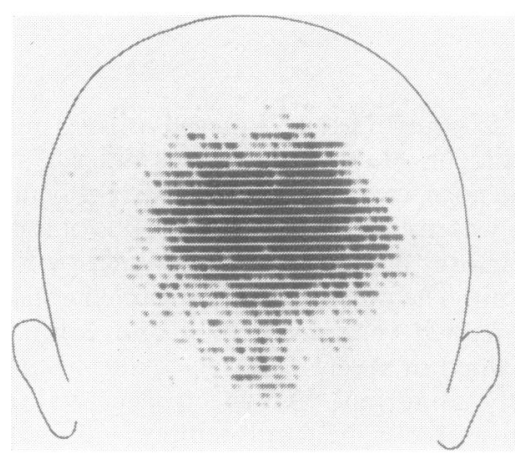

(e)

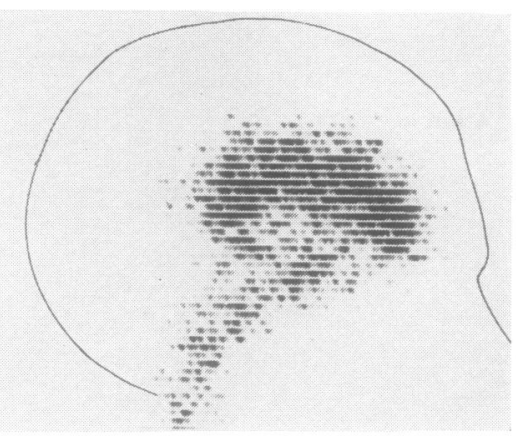

(b)

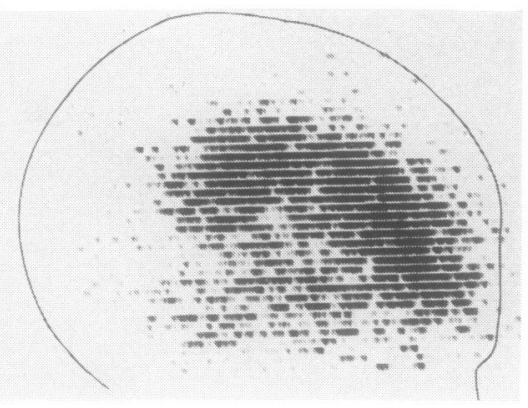

(d)

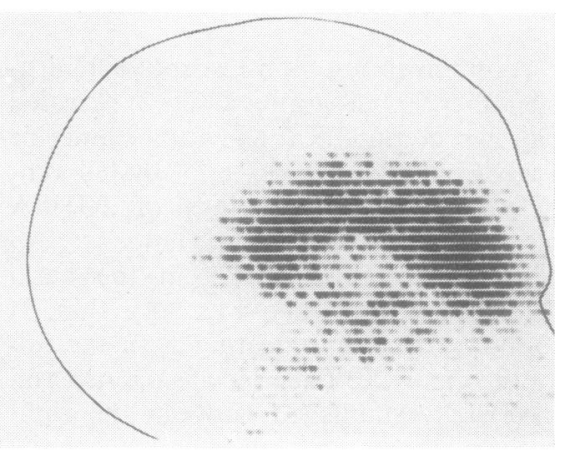

(f)

FIG. 3. RIHSA cisternography. Case 2. Porencephalic cyst and hydrocephalus. (a) Anterior and (b) lateral views at four hours. The radiopharmaceutical fills the basal cisterns and enlarged ventricles. An accumulation of $\mathrm{O}$ radioactivity is seen lateral to the left ventricle in the anterior view, and anterior to it in the lateral view, repre- $>$ senting early filling of the cyst. (c) Anterior and (d) lateral views at 24 hours. The radiopharmaceutical outlines $\frac{}{0}$ the lateral ventricles and fills the porencephalic cyst more completely. No radioactivity is recorded over the brain convexities. (e) Anterior and (f) lateral views at 48 hours. The radiopharmaceutical fills the whole extent $\mathrm{S}$ of the cyst and the enlarged lateral ventricles. A very large amount of radioactivity still remains in the head. 


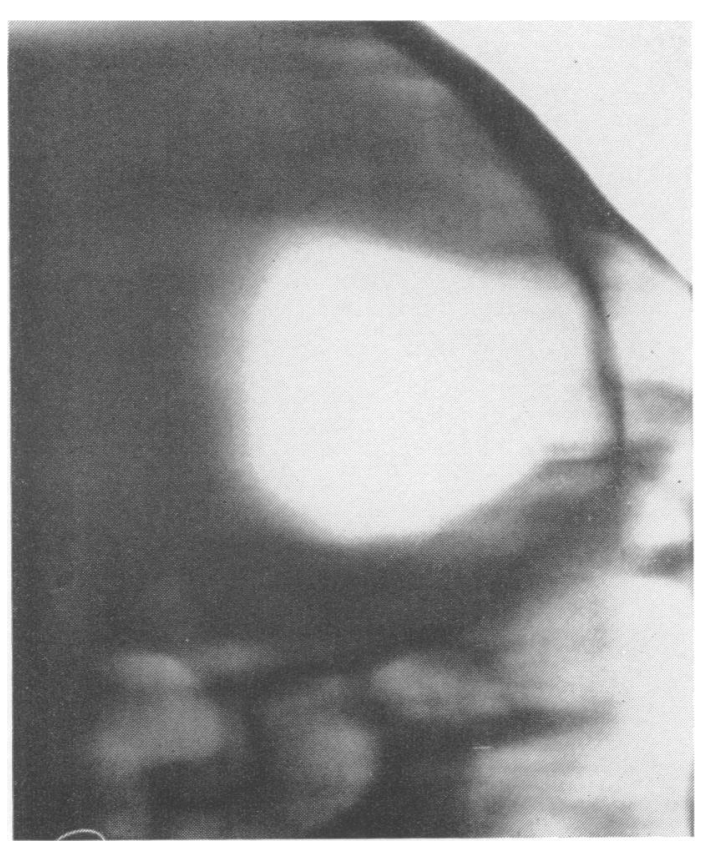

FIG. 4. Pneumoencephalography. Case 2. Porencephalic cyst and hydrocephalus. Lateral tomogram demonstrating the frontal cyst in continuity with an enlarged left lateral ventricle.

ventricle; this accumulation was even more evident at 48 hours.

The focal abnormality was taken to indicate a large porencephalic cyst communicating with the right lateral ventricle. The filling of the ventricles and the lack of any radioactivity over the convexities were thought to be the signs of communicating nonresorptive hydrocephalus.

At operation a cyst of the right frontal lobe was found, with a narrow communication between the cyst and the frontal horn of the right lateral ventricle. The basal cortex of the right frontal horn was excised, and a pathway was established between the right ventricle and the subarachnoid space.

There was a significant improvement in headaches, mental state, and the gait after the operation.

\section{DISCUSSION}

Porencephaly, to use the definition of Le Count and Semerak (1925), is 'a defect communicating with the ventricles or separated from them by a thin layer of brain tissue and covered on the outside by the arachnoid'. Generally, however, the term is used to describe any defect in the brain tissue communicating with the ventricles (Pendergrass and Perryman, 1946; Naef, 1958; Barrett and Mendelsohn, 1965; Hamer and Piscol, 1971).

According to their aetiology, porencephalic cysts are divided into developmental and acquired (Naef, 1958). Acquired cysts are the result of destruction of cerebral tissue from various causes, such as trauma, vascular insufficiency or infection. In cases 1 and 3 the cysts were probably the result of trauma, and case 2 was known to have recurrent bouts of meningitis.

These cysts, although sometimes 'silent', often cause a variety of clinical symptoms, and may progress in size (Drew and Grant, 1948; Handa and Bucy, 1956; Naef, 1958; Barrett and Mendelsohn, 1965; Cantu and Le May, 1967; Hamer and Piscol, 1971). These facts, to use the words of Barrett and Mendelsohn (1965) 'justify more vigorous attempts at early diagnosis and treatment'.

Pneumoencephalography is the usual method for the diagnosis of porencephaly, but it may not always reveal the full extent of the lesion (Pendergrass and Perryman, 1946). Even when a meticulous technique is employed it may completely fail to demonstrate the cyst, as happened in case 3 . The small opening by which the cyst communicated with the lateral ventricle probably explains why air failed to enter it. RIHSA, as shown in our cases, enters the cysts easily and demonstrates their communication with the ventricle and their size. The manoeuvring and different positioning used in pneumoencephalography or ventriculography are not necessary. Large experience has shown that isotope cisternography is a simple and harmless method (Front, 1971).

RIHSA investigations in our patients showed that, in addition to a porencephalic cyst, they had a hydrocephalus of the communicating nonresorptive type, due to obstruction to CSF flow over the cerebral convexities. This association was also reported by Hamer and Piscol (1971) who were unable to determine the nature of the hydrocephalus. In our cases the hydrocephalus was caused by post-traumatic subarachnoid haemorrhage in two cases and by meningitis in the third. Such disorders lead to meningeal adhesions and obliteration of the subarachnoid space, so 


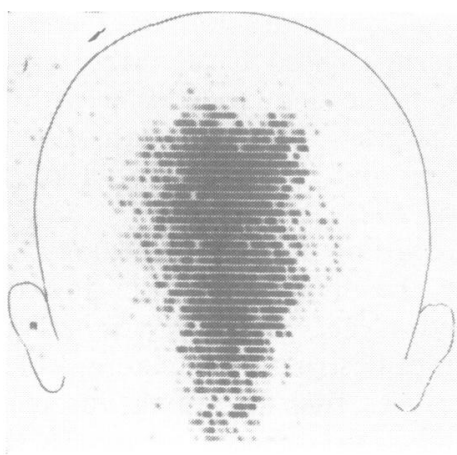

(a)

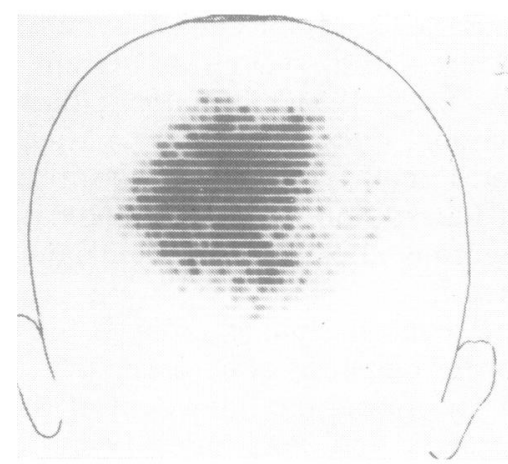

(c)

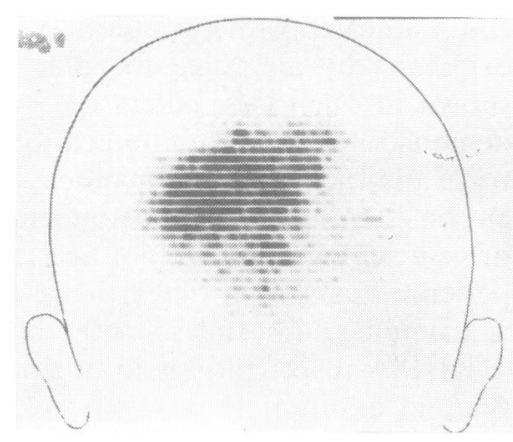

(e)

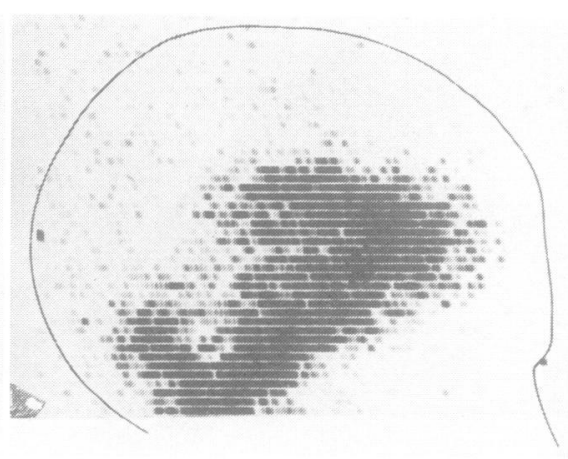

(b)

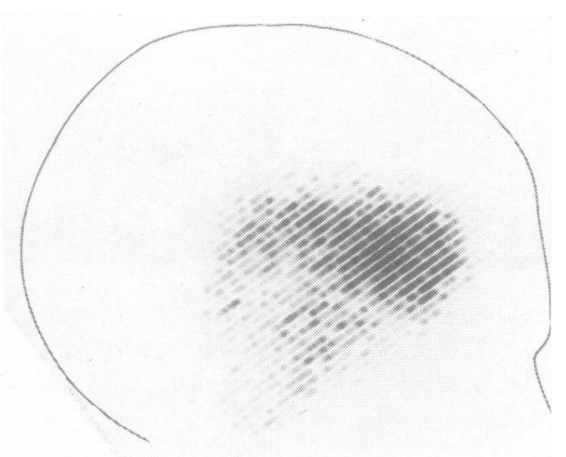

(d)

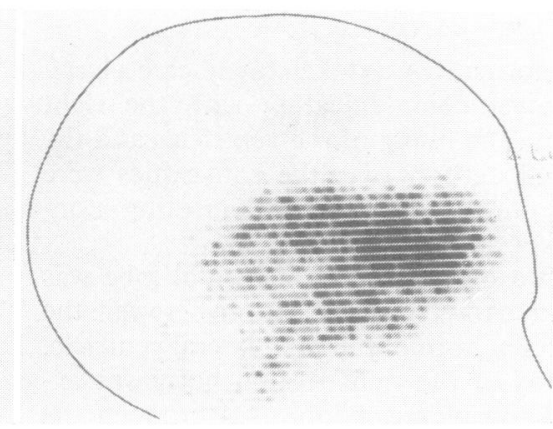

(f)

FIG. 5. RIHSA cisternography. Case 3. Porencephalic cyst and hydrocephalus. (a) Anterior and (b) laterą่ views at four hours. The radiopharmaceutical fills the cisterna magna, basal cisterns, and enlarged lateral ven tricles. An accumulation of radioactivity is seen lateral to the right ventricle in the anterior view, and the latera? view shows that it is in continuity with the anterior horn. This represents early filling of the cyst. (c) Anteriors and (d) lateral views at 24 hours. The radiopharmaceutical fills the lateral ventricles and a large cyst lateral to․ the right ventricle in the frontal region. No radioactivity is recorded from the brain convexities. (e) Anterior and (f) lateral views at 48 hours. The radiopharmaceutical is mainly in the cyst. Radioactivity is also recorded from $P$ the ventricles. There is no radioactivity over the brain convexities. 
that CSF and RIHSA can no longer reach the normal site of absorption along the superior sagittal sinus. They are then absorbed by an alternative mechanism, through the walls of the ventricles (Wislocki and Putnam, 1921; Bering and Sato, 1963; Sahar, Hochwald, and Ransohoff, 1969; Sahar, Hochwald, and Ransohoff, 1970; Front, 1971). This transventricular absorption is thought to account for the flow of CSF and RIHSA into the ventricles. As RIHSA injected in the lumbar region does not enter the ventricles in normal individuals, the visualization of the porencephalic cysts in our cases was made possible by the simultaneous presence of nonresorptive hydrocephalus. As shown in Figs le and $\mathrm{f}, 3 \mathrm{e}$ and $\mathrm{f}, 5 \mathrm{e}$ and $\mathrm{f}$, a large amount of radioactivity remained in the cysts at 48 hours. It seems probable, therefore, that CSF and RIHSA are only slowly absorbed through the cyst wall or that they have to reenter the ventricles in order to be absorbed.

\section{CONCLUSION}

When associated with non-resorptive communicating hydrocephalus isotope cisternography can provide information about the size, site, and communication of porencephalic cysts and, when air fails to enter the cyst, it may be the only means of making the diagnosis. It also demonstrates that the associated hydrocephalus is caused by disturbances in CSF flow and absorption; this information is essential for adequate neurosurgical treatment.

\section{REFERENCES}

Bannister, R., Gliford, E., and Kocen, R. (1967). Isotope encephalography in the diagnosis of dementia due to communicating hydrocephalus. Lancet, 2, 1014-1017.

Barrett, J. W., and Mendelsohn, R. A. (1965). Post-traumatic porencephaly in infancy. A report of three unusual cases. Journal of Neurosurgery, 23, 522-527.

Bering, E. A. Jr., and Sato, O. (1963). Hydrocephalus: changes in formation and absorption of cerebrospinal fluid within the cerebral ventricles. Journal of Neurosurgery, 20, 1050-1063.

Cantu, R. C., and LeMay, M. (1967). Porencephaly caused by intracerebral hemorrhage. Radiology, 88, 526-530.

Di Chiro, G., Reames, P. M., and Matthews, W. B. Jr. (1964). RISA-ventriculography and RISA-cisternography. Neurology, 14, 185-191.

Di Chiro, G., and Grove, A. S. Jr. (1966). Evaluation of surgical and spontaneous cerebrospinal fluid shunts by isotope scanning. Journal of Neurosurgery, 24, 743-748.

Di Chiro, G., Ommaya, A. K., Ashburn, W. L., and Briner, W. H. (1968). Isotope cisternography in the diagnosis and follow-up of cerebrospinal fluid rhinorrhea. Journal of Neurosurgery, 28, 522-529.

Drew, J. H., and Grant, F. C. (1948). Benign cysts of the brain. An analysis with comparison of results of operative and non-operative treatment in thirty cases. Journal of Neurosurgery, 5, 107-123.

Front, D. (1971). Scinticisternography and scintiventriculography. Thesis, University of Groningen, The Netherlands.

Front, D., and Penning, L. (1971). Occult spontaneous cerebrospinal fluid rhinorrhoea diagnosed by isotope cisternography. Neuroradiology, 2, 167-169.

Hamer, J., and Piscol, K. (1971). Die Bedeutung des ventrikulo-atrialen Shunts in der Behandlung der wachsenden Porenzephalie. Acta Neurochirurgica, 24, 187-200.

Handa, H., and Bucy, P. C. (1956). Benign cysts of the brain simulating brain tumor. Journal of Neurology, 13, 489-499.

James, A. E. Jr., DeLand, F. H., Hodges, F. J. III, and Wagner, H. N. Jr. (1970). Normal-pressure hydrocephalus. Role of cisternography in diagnosis. Journal of the American Medical Association, 213, 1615-1622.

LeCount, E. R., and Semerak, C. B. (1925). Porencephaly. Archives of Neurology and Psychiatry, 14, 365-383.

Naef, R. W. (1958). Clinical features of porencephaly. A review of thirty-two cases. Archives of Neurology and Psychiatry, 80, 133-147.

Pendergrass, E. P., and Perryman, C. R. (1946). Porencephaly. American Journal of Roentgenology, 56, 441463.

Sahar, A., Hochwald, G. M., and Ransohoff, J. (1969). Alternate pathway for cerebrospinal fluid absorption in animals with experimental obstructive hydrocephalus. Experimental Neurology, 25, 200-206.

Sahar, A., Hochwald, G. M., and Ransohoff, J. (1970). Passage of cerebrospinal fluid into cranial venous sinuses in normal and experimental hydrocephalic cats. Experimental Neurology, 28, 113-122.

Wislocki, G. B., and Putnam, T. J. (1921). Absorption from the ventricles in experimentally produced internal hydrocephalus. American Journal of Anatomy, 29, 313-320. 